the satellites have produced a large yield of high quality information. In others, initial goals have proved to be over-optimistic. In particular, it has proved far more difficult than predicted to use satellites for assessing agricultural yields - for example because of problems in distinguishing between different types of crops - and more research is now being done in this area.

Enough information has been gained so far, however, to convince the US that remote sensing can provide useful information to developing countries in fields from water resource engineering (such as building dams or irrigation systems) to mineral prospecting. The US Agency for International Development (AID) has already carried out research projects and training in more than 30 countries, demonstrating how Landsat data can be used by local planners and policy-makers.

Speaking in Vienna last week after Father Hesburgh's address, Mr Tom Pickering, director of the State Department's Bureau of Oceans and the Environment, said that in announcing its new initiative, the US had two main goals, both of which were intended to held

\section{Interference with data from Titan}

Vital data on the surface temperature of Saturn's giant moon Titan may have been lost as the result of radio interference during the transmission of the data from the Pioneer 11 spacecraft to the National Aeronautics and Space Administration's Ames Research Center in California last week. In place NASA has a series of dollar signs, printed by the computer receiving the data as an indication that it was unintelligible.

At first it was thought that all the relevant data, which came from readings made by an infrared radiometer aboard the spacecraft and would provide important clues about the planet's atmosphere, had been lost. However subsequent investigation showed that the data had been received - but in a highly garbled form. NASA scientists are now trying to unscramble what they can; they are confident that some of the information can be retrieved, but remain uncertain about its quality.

"The data was ratty, make no mistake about that. But it's there, and it may all be there, all 20 minutes of it, ground up in some scrambled data that was fouled in the communication link between Madrid (one of the three receiving stations for Pioneer transmissions) and California," mission chief scientist Dr John Wolfe said last Thursday.

Late last week, the precise cause of the radio interference was still uncertain. Initially it was stated that the interference had been caused by a Soviet satellite in Earth orbit, Cosmos 1124, which NASA developing countries make better use of remote sensing data.

The first goal is to bring together the various countries now planning their own satellite systems to ensure the maximum possible complementarity and compatibility. The aim, for example, would be to ensure not only the minimum of overlap and duplication, but also that wherever possible a developing country receiving station could use the same equipment for receiving data from different satellites.

The second goal is to bring together, possibly on a regional basis, those who intended to use satellite data to obtain information about their own resources, and how these might best be managed. "Our hope is that through discussion with users we can define together the sort of data that can be most effective in answering their needs, and in discovering about their own territories the type of things that they would like to discover," Mr Pickering said.

The Administration's decision was welcomed by Senator Adlai Stevenson Jr, chairman of the Senate's Science and Space Subcommittee, who has long been a critic of the current Administration's lack of plans for an operational Earth-monitoring

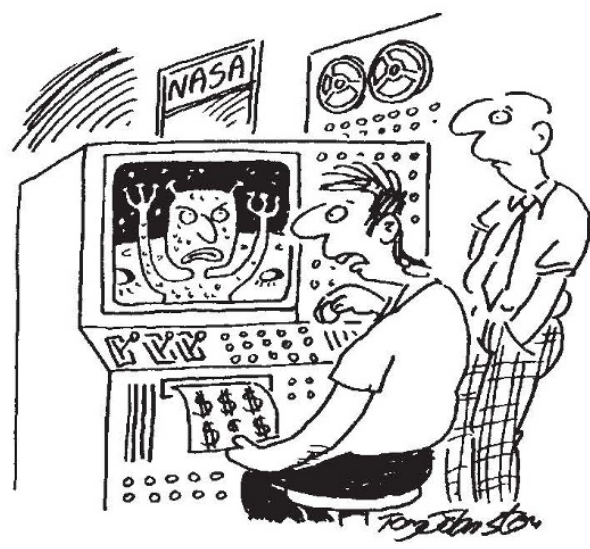

"It's the Titans! They say if we want to take pictures we can pay for them!"

officials had forgotton to ask Soviet scientists to switch off during the period in which the Pioneer data was being transmitted.

On Wednesday, the space agency issued a statement identifying the satellite as the cause of the problem. The statement continued: "NASA officials indicate that they have no doubt that the Soviets would have avoided the conflict on Monday, if they had been asked. However the impact of the potential interference was not recognised in time to make an additional request to the Soviets."

By the next day, however, NASA had changed its mind about the cause of the interference. Rather than the Soviet satellite, they now blamed the combined effect of a solar storm and low quality land transmissions between Spain and California - an explanation which had been put forward at the very beginning, but rejected when the Cosmos satellite's involvement had become known. satellite system, advocating this as one of the most important areas in which US technology can help developing countries.

Describing the wide potential applications of remote sensing, $\mathrm{Mr}$ Stevenson said that the US "was concerned that these technologies will follow many national courses and that, if some cooperative steps are not taken soon, it may be too late to at least develop complementary technologies. By complementary we mean not only the physical systems, but also in their operation, so that satellites can be used in a way that avoid redundancies and maximises knowledge of the resources of the world."

Backing up the proposal made in Father Hesburgh's speech, AID mounted an exhibition in Vienna demonstrating the type of data that can be derived from Landsat and other satellites, and the way in which it might be used. The exhibition was to have been entitled "remote sensing: an appropriate technology for economic development" - until advocates in AID of a less capital-intensive approach to Third World needs objected, and the word "appropriate" was dropped from the title.

David Dickson

\section{Bulgaria plans to save energy}

During the next Five Year Plan (1981-1985), all Bulgarian "energy consuming enterprises" will become subscribers to Promishlena Energetika (Industrial Energy), an organisation established this summer and described by Energy Minister Nikola Todoriev as " $a$ scientific production combine". The main purpose of Promishlena Energetika is the saving of all forms of energy across the economy; its activities range from the reconstruction and modernisation of existing inatallations to an extensive research and development programme.

What precise form this research would take, the Minister did not specify. He was addressing a symposium on "Fuel and Energy saving and new energy resources" held in conjunction with the annual Plovdiv trade fair. Scientific seminars at the Fair were introduced some ten years ago, and, according to Penko Penkov, Chairman of the Bulgarian Chamber of Commerce, are the response of the organisers to the information explosion.

"Rapid technical progress makes us organise sceintific and technical symposia", said Penkov, "in order to give experts from many countries a chance to keep up with the latest developments". This year, there were no less than twelve day or half-day seminars on subjects ranging from ergonomics, geodesy, and the stimulation of scientific creativity to textile and leather technology and the bacteriology of yoghourt. The three day energy symposium, however, with its massive foreign participation and the full 